\title{
Lead Extraction in Children and Young Adults Using Different Techniques
}

\author{
Embiya Dilber $^{\mathrm{a}}$ Tevfik Karagöz $^{\mathrm{b}}$ Alpay Çeliker ${ }^{\mathrm{b}}$ \\ Department of Pediatrics, Faculty of Medicine, ${ }^{a}$ Karadeniz Technical University, Trabzon, and \\ ${ }^{\mathrm{b}}$ Hacettepe University, Ankara, Turkey
}

\author{
Key Words \\ Lead extraction · Pacemaker lead · Percutaneous \\ pacemaker lead removal
}

\begin{abstract}
Objective: To describe our experience with removal of pacing lead in children using different techniques. Patients and Methods: Between 1999 and 2006, removal of 39 leads was attempted in 30 patients: 21 males and 9 females aged 4-21 years (mean $12 \pm 5$ years). Sixteen patients had previous corrective cardiac surgery. The leads had been implanted for 46 \pm 31 months (range 1-120 months). The reasons for removal included lead fracture in 14, upgrading in 8 , infection in 7 , dislodgment in 5, pacing system not needed in 2, and other reasons in 3. Results: Of the 39 leads, 29 (74.3\%) were completely removed. Twelve leads were removed with simple traction and rotation and 9 were removed using a locking stylet combined with simple traction and rotation; a laser extraction system was used in 10 cases in which 8 leads were successfully removed. Duration of implantation was the only important predictor for successful removal. Three patients necessitated surgical lead removal and had epicardial pacemaker implantation. Conclusion: Using currently available techniques, percutaneous pacemaker lead removal was possible in the majority of cases, although a significant number of cases were not successful. Attempted lead removal with simple traction and rotation resulted in the need for surgical removal in a significant number of patients. Newer techniques should be developed to increase the success rate.
\end{abstract}

Copyright $\odot 2009$ S. Karger AG, Basel

\section{KARGER}

Fax +4161306 1234

E-Mail karger@karger.ch

www.karger.com
(C) 2009 S. Karger AG, Basel

1011-7571/09/0185-0356\$26.00/0

Accessible online at:

www.karger.com/mpp

\section{Introduction}

Transvenous-endocardial pacing has become standard practice for children who require pacemaker therapy. Pacing leads are typically inserted through the subclavian vein down to the right atrium or right ventricle. During follow-up, lead malfunction, growth of the patient and loss of lead slack with potential for lead dislodgement, and infection of the pacing system may necessitate replacement of the lead [1-3]. As the life expectancy of patients with pacemakers increases, several lead revision procedures may be needed during their lifetime. Abandoned leads may interfere with normal cardiac function and cause obstruction in the upper venous system [4]. The purpose of this study was to report our experience with the removal of permanent pacing leads using different techniques in children and young adults.

\section{Patients and Methods}

All the 30 patients in whom lead removal was attempted were included in this report. Between June 1999 and April 2006, removal of 39 leads was attempted in the 30 patients (21 males, 9 females, mean age $12 \pm 5$, range $4-21$ years). The procedures were performed in the cardiac catheterization laboratory. The electrocardiogram and oxygen saturation were monitored continuously. Arterial blood pressure was monitored using a femoral artery catheter. In pacemaker-dependent patients, a temporary pacing wire was inserted through the femoral vein. Blood products were 
Table 1. Baseline characteristics ( $\mathrm{n}=39$ leads, 30 patients)

\begin{tabular}{ll}
\hline Characteristics & \\
\hline Age at time of extraction, years & $12 \pm 5(4-21)$ \\
Prior cardiac surgery & 16 \\
Primary rhythm abnormality & 14 \\
Indication for lead extraction & \\
$\quad$ Lead fracture & 14 \\
Upgrading & 8 \\
Infection & 7 \\
Dislodgement & 5 \\
Pacing system not needed & 2 \\
Others & 3 \\
\hline
\end{tabular}

also available in the catheterization room. Local anesthesia was achieved with lidocaine and sedation was achieved with midazolam and ketamine. After sterile preparation of the overlying skin, the generator pocket was dissected open and the pacemaker generator was disconnected from the leads and removed. For patients requiring replacement of their lead, a new lead system was implanted through the same vein, or in some patients via the subclavian vein on the opposite side.

A superior venous approach was tried first in all patients using the previously described techniques including rotation and simple traction, and/or locking stylet. Following an unsuccessful subclavian extraction, the femoral approach was tried in some cases. The laser extraction system was used in 10 patients.

After the procedure, the patients were monitored overnight in the pediatric ward. All patients had a postprocedure chest roentgenogram, determination of hemoglobin as well as an echocardiogram to rule out hemopericardium and to evaluate atrioventricular valve function.

\section{Results}

Of the 30 patients, 16 had had corrective cardiac surgery for congenital heart disease. Five of these had had previous epicardial pacemaker implantation (table 1). The remaining 14 patients had primary rhythm abnormalities and had no underlying structural heart disease. Leads had been implanted for $46 \pm 31$ months (range 1-120 months) (table 2). Leads were inserted through the right subclavian vein in 26 and the left subclavian vein in 13. The reasons for extraction included lead fracture in 14 , upgrading in 8 , infection in 7 , dislodgement in 5 , pacing system not needed in 2 , and other in 3 . Lead characteristics are shown in table 2.

Of the 39 leads, 29 (74.4\%) were completely removed. Twelve leads were removed with simple traction and rotation and 9 were removed using a locking stylet combined
Table 2. Lead characteristics

\begin{tabular}{ll}
\hline Lead characteristics & \\
\hline Total number of leads & 39 \\
Time from implantation, months & $46 \pm 31(1-120)$ \\
Lead type & \\
$\quad$ Atrial & 6 \\
$\quad$ Ventricular & 33 \\
Side of implantation & \\
$\quad$ Right & 26 \\
$\quad$ Left & 13 \\
Fixation & \\
$\quad$ Active & 22 \\
$\quad$ Passive & 17 \\
Polarity & \\
$\quad$ Bipolar & \\
$\quad$ Unipolar & 23 \\
\end{tabular}

${ }^{1}$ Includes only cases in which information was available.

with simple traction and rotation (fig. 1). A femoral approach was additionally used in 5 of these patients. The laser extraction system was used in 10 cases, in which 8 leads were successfully removed. Laser extraction failed in 2 patients due to inability to pass through the subclavian vein into the superior vena cava. New leads were inserted during the same procedure in 34 cases. The same subclavian vein was used in 18 patients and the opposite subclavian vein was used in the remaining 16 patients.

In 2 of the 10 unsuccessful attempts at removal, the lead tip could not be unscrewed from the heart. In another 7 cases, the leads could be withdrawn neither from the heart nor from the superior venous system. Three patients underwent surgical lead removal. Two of them had severely deformed leads at the level of the tricuspid valve and the other had lead attachment to the tricuspid valve. Transthoracic echocardiography revealed prominently increased tricuspid regurgitation in all patients compared to the previous echocardiographic study. Epicardial pacemakers were implanted in the 3 patients in whom surgical lead removal was performed.

No life-threatening complication occurred in any patient during the removal and early follow-up. However, the 3 patients who had surgical lead removal underwent epicardial pacemaker implantation. In all these patients, lead removal was tried with simple traction and rotation. The patients were followed postoperatively by our clinic for 1-120 months (mean $47 \pm 29$ ). In leads implanted less than 3 years before removal, the success rate was $100 \%$, 
Fig. 1. Lead traction techniques and suc-

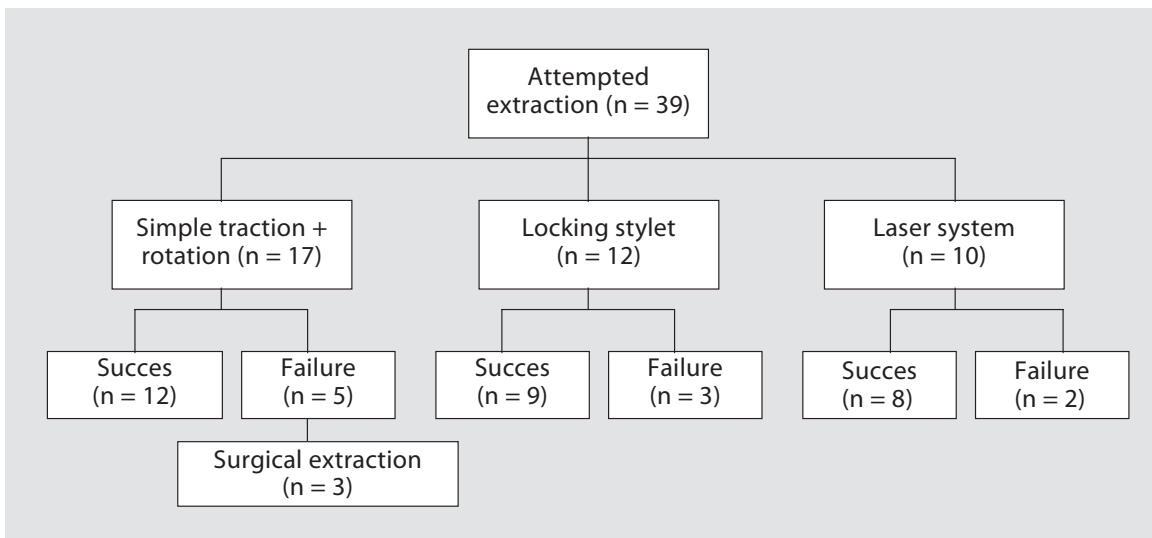
cess rate.

and in 3-year or older leads, the success rate was $65.5 \%$. All atrial leads were successfully removed. The success rate in ventricular leads was $69.7 \%$.

\section{Discussion}

Nonfunctioning pacing leads remain an important problem in the era of cardiac pacing. Abandoned leads may interfere with normal cardiac function and cause obstruction of venous drainage in the upper part of the body [4]. The old leads may also interfere with the insertion of new leads [2]. A permanent pacemaker needed in early life increases this problem and necessitates lead replacement during lifetime. However, attempting to remove the old pacemaker leads by simple traction and rotation may sometimes have undesired consequences such as surgical removal in some patients, as in our study.

Infection of the pacing system is the leading cause for lead removal in adult patients $[5,6]$. In contrast, lead malfunction as a result of trauma to the lead and subsequent damage to the insulation or wire components is the most common indication for lead removal in the younger age group $[1,2]$. Moreover, some children necessitate implantation of a permanent pacemaker before the adolescent growth spurt. Depending on the extent of their growth, an excess lead left within the heart may be insufficient and cause lead dislodgement. In our report, the most common indication for lead removal was lead fracture, followed by upgrading and pacing system infection. Five patients also needed lead removal for dislodgement, possibly due to adolescent growth.

Different methods are now available for lead removal. The first method developed was simple traction and rota- tion. This technique usually has low success as confirmed by our study in which only 12 leads were completely removed using this technique. A high complication rate including damage to the myocardium, tricuspid valve or to the venous system have been reported as we experienced in 3 patients who later underwent surgical lead removal and implantation of epicardial pacemakers.

With the increasing requirement of lead removal, new techniques were developed to improve the success rate and reduce complication. The locking stylet has the advantage of improving traction at the top of the lead and stiffening the lead; we successfully removed 9 leads using this technique. The laser extraction system has been in use since 1994, and separates the lead from the adhesions with a high success rate. This technique has significant clinical advantages over extraction using nonpowered sheats and has been successfully used in cases in which other techniques failed $[2,6,7]$; we used it successfully in 8 of 10 cases.

Duration of implantation time is the most important parameter in predicting the success rate in lead removal $[8,9]$. Scar tissue increases with time and contributes to an increased complication rate and decreases success rate [10]. Implantation times of $46 \pm 31$ months in our patients did not differ significantly from those of previous series (42-56 months) [1, 2, 11]. Implantation durations of less than 3 years had a success rate of $100 \%$ whereas it was only $65.5 \%$ in those that were older than 3 years, most probably due to our young patient population. Fibrous tissue is more robust in these patients, and it has been reported that younger patients were less likely to have leads completely removed [8]. Equally important is the fact that we used nonlaser systems in the majority of our patients. 


\section{Conclusion}

Using currently available techniques, percutaneous pacemaker lead removal was possible in the majority of cases although a significant number of attempted remov- als were not successful. Attempted lead removal with simple traction and rotation resulted in the need for surgical removal in a significant number of patients. Newer techniques should be developed to increase the success rate.

\section{References}

$>1$ Friedman RA, Van Zandt H, Collins E, LeGras M, Perry J: Lead extraction in young patients with and without congenital heart disease using the subclavian approach. Pacing Clin Electrophysiol 1996;19:778-783.

$>2$ Moak JF, Freedenberg V, Ramwell C, Skeete A: Effectiveness of excimer laser-assisted pacing and ICD lead extraction in children and young adults. Pacing Clin Electrophysiol 2006;29:461-466.

$>3$ Love CJ, Wilkoff BL, Byrd CL, Belott PH, Brinker JA, Fearnot NE, Friedman RA, Furman S, Goode LB, Hayes DL, Kawanishi DT, Parsonnet V, Reiser C, Van Zandt HJ: Recommendation for extraction of chronically implanted transvenous pacing and defibrillator leads: indications, facilities, training. Pacing Clin Electrophysiol 2000;23:544551.

4 Spittell PC, Hayes DL: Venous complications after insertion of a transvenous pacemaker. Mayo Clin Proc 1992;67:258-265.
Moon MR, Camillo CJ, Gleva MJ: Laserassist during extraction of chronically implanted pacemaker and defibrillator leads. Ann Thorac Surg 2002;73:1893-1896.

$\checkmark 6$ Wilkoff BL, Byrd CL, Love CJ, Hayes DL, Sellers TD, Schaerf R, Parsonnet V, Epstein LM, Sorrentino RA, Reiser C: Pacemaker lead extraction with the laser sheat: results of the pacing lead extraction with the excimer sheat (PLEXES) trial. J Am Coll Cardiol 1999;33:1671-1676.

7 Byrd C, Wilkoff B, Love C, Hayed D, Sellers D, Schaerf R, Epstein L: Clinical study of the laser sheat: results of the PLEXES trial (abstract). Pacing Clin Electrophysiol 1997;20: 1053.

$\checkmark 8$ Byrd CL, Wilkoff BL, Love CJ, Sellers TD, Turk KT, Reeves R, Young R, Crevey B, Kutalek SP, Freedman R, Friedman R, Trantham J, Watts M, Schutzman J, Oren J, Wilson J, Gold F, Fearnot NE, Van Zandt HJ R: Intravascular extraction of problematic and infected permanent pacemaker leads: 19941996. US Extraction Database, MED Institute. Pacing Clin Electrophysiol 1999;22: 1348-1357.
9 Parsonnet V, Roelke M, Trivedi A, Rizvi SA, Pervez A: Laser extraction of entrapped leads. Pacing Clin Electrophysiol 2001;24: 329-332.

10 Candinas R, Duru F, Schneider J, Lüscher TF, Stokes K: Postmortem analysis of encapsulation around long-term ventricular endocardial pacing leads. Mayo Clin Proc 1999; 74:120-125.

11 Cooper JM, Stephenson EA, Berul CI, Walsh EP, Epstein LM: Implantable cardioverter defibrillator lead complications and laser extraction in children and adults with congenital heart disease: Implications for implantation and management. J Cardiovasc Electrophysiol 2003;14:344-349. 